http://dx.doi.org/10.30681/23588403v14i0115

\title{
LETRAMENTO CRÍTICO NO PLANEJAMENTO DE AULAS DE INGLÊS: PROMOVENDO O "LER, SE LENDO"
}

\author{
Nayara Stefanie Mandarino SILVA (UFS) ${ }^{1}$ \\ Thainná Melo NUNES (UFS) ${ }^{2}$
}

Data de recebimento: $20 / 08 / 2020$

Data de aceite: $03 / 11 / / 2020$

\begin{abstract}
Resumo: Levando em consideração as ressignificações do conceito de língua e, com isso, as mudanças ocorrentes no ensino, abordamos a visão da teoria do Letramento Crítico, que entende a língua como construção de sentidos e defende a importância do incentivo à reflexão na sala de aula. O objetivo deste artigo é discutir o planejamento de aulas, com base na teoria do Letramento Crítico, considerando formas de estimular o aluno a "ler, se lendo" (MENEZES DE SOUZA, 2011a). Para tanto, discutimos a definição da teoria com base em Janks (2012), Jordão (2013) e Menezes de Souza (2011b) e analisamos um plano de aula elaborado no contexto de uma disciplina de estágio supervisionado de língua inglesa, ofertada pela Universidade Federal de Sergipe, em 2018. A metodologia utilizada nesta pesquisa foi qualitativa bibliográfica, baseada na pesquisa-ação (BURNS, 2015; LAVILLE, DIONNE, 1999).
\end{abstract}

Palavras-chave: Letramento Crítico. Planejamento de aulas. Língua Inglesa.

Abstract - Considering the resignifications of language concepts and, consequently, the changes that have occured in teaching practices, we approach the concept of Critical Literacy, which understands language as meaning-making process and defends the importance of reflecting in the classroom. The objective of this paper is to discuss lesson planning based on the Critical Literacy theory, considering ways of stimulating students to "read, reading themselves" (MENEZES DE SOUZA, 2011a). In order to do so, we discuss the theory based on Janks (2012), Jordão (2013), and Menezes de Souza (2011b). We also analyze a lesson plan elaborated in a course of supervised practice in the English language, offered by the Federal University of Sergipe, in 2018. The methodology used in this research was qualitative and bibliographic, based on action-research (BURNS, 2015; LAVILLE, DIONNE, 1999).

Keywords: Critical Literacy. Class Planning. English Language.

\section{Introdução}

O conceito de língua passou por mudanças durante os anos, sendo ressignificado diversas vezes. No século XX, com a influência dos estudos behavioristas associados a Ivan

1 Graduada em Letras Português e Inglês (Universidade Federal de Sergipe). E-mail: nayaramandarino@hotmail.com

${ }^{2}$ Graduada em Letras Português e Inglês (Universidade Federal de Sergipe). E-mail: thainna506@ gmail.com 
Pavlov e B. F. Skinner, ela era entendida como um conjunto de comportamentos sociais adquirido através da formação de hábitos e da exposição a estímulos. Nesse contexto, o aprendizado ocorreria pela transmissão de conhecimento do professor para o aluno, que os recebia passivamente. (RICHTER, 2002). Esse tipo de prática de ensino é discutido por Freire (1987-1994, p. 33) e denominado "concepção bancária da educação" - os alunos recebem depósitos de conhecimento dos professores, que preenchem as suas cabeças vazias. Segundo o autor, essa concepção contribui com a opressão, pois não estimula a consciência crítica dos alunos.

Com os avanços dos estudos cognitivistas, com Jean Piaget como um dos precursores, e com as pesquisas de Noam Chomsky, a língua passa a ser considerada inata ao ser humano que desenvolve a língua ao ser exposto a ela. Os processos mentais passam a ser considerados e os alunos são mais centralizados na aula. Vygotsky (1984), após estudar Piaget, defende que o conhecimento é construído através das interações sociais, nas quais a linguagem tem papel decisivo. A língua, portanto, passa a ser entendida como instrumento de comunicação (SCHULZ; CUSTODIO; VIAPIANA, 2012).

Os estudos pós-estruturalistas e as noções de discurso propostas por Foucault (19702012) fomentam discussões sobre língua e as relações de poder e ideologias que a permeiam, desse modo, a verdade é questionada; como afirmar que algo é verdade se existem diferentes ideologias, vivências e crenças? Nesse contexto, reconhece-se que os limites entre língua, sociedade, cultura e poder não são claros; não é possível determinar onde um termina e o outro começa, eles se relacionam complexamente (JORDÃO, 2007). Com essas questões em mente, o ensino de línguas deve consistir em um conjunto de práticas que vá além da língua entendida isoladamente; é necessário considerar o que está intrinsecamente relacionado a ela. É o que propõe a teoria do Letramento Crítico, que visa estimular reflexões sobre como construímos sentidos e como nos relacionamos com a sociedade em que vivemos e com a qual interagimos.

Desse modo, este artigo tem como objetivo discutir o planejamento de aulas, com base na teoria do letramento crítico, considerando formas de estimular o aluno a "ler, se lendo" (MENEZES DE SOUZA, 2011a). Para tanto, discutimos a definição da teoria com base em Janks (2012), Jordão (2013) e Menezes de Souza (2011b) e analisamos um plano de aula elaborado no contexto de uma disciplina de estágio supervisionado de língua inglesa, ofertada pela Universidade Federal de Sergipe, em 2018. Este artigo trata de uma pesquisa qualitativa bibliográfica, baseada na pesquisa-ação (BURNS, 2015; LAVILLE, DIONNE, 1999). 


\section{Definindo letramento crítico}

De acordo com Jordão (2013), a palavra letramento começou a ser usada na década de 1980, configurando, desse modo, uma discussão recente. A autora afirma que o termo pode ser definido como práticas de leitura e escrita mais complexas que a decodificação do sistema de escrita - a alfabetização. O termo recebeu diferentes abordagens; aqui discutimos o Letramento Crítico (doravante LC), que tem base nas obras do autor brasileiro Paulo Freire.

Foucault (1969-2008), ao tratar de enunciados - que, em conjunto, formam os discursos, afirma que nós os reproduzimos e os transformamos em seus diversos sentidos. $\mathrm{O}$ autor defende que a validação de um enunciado como verdadeiro depende do tempo e espaço em que são ditos; por exemplo, era considerado verdade afirmar que a terra é o centro do universo (geocentrismo) no ano de 1400, na Polônia, no entanto, essa afirmação não teria caráter de verdade reconhecido em 2019, no Brasil. As verdades discursivas também estão relacionadas a relações de poder que é distribuído desigualmente, segundo Foucault (19692008). Desse modo, em uma audiência judicial, o que é dito por um juiz tem validade maior do que o que é dito por um réu, devido à relação de poder dentro desse contexto. Porém, em outro contexto, o réu pode deter maior poder com relação a outras pessoas, se ele é dono de uma empresa com funcionários, por exemplo. Portanto, o reconhecimento de discursos como verdadeiros dependem do tempo e espaço em que estão inseridos e do papel que assumem os sujeitos que os emitem no contexto da enunciação. Foucault (1970-2012, p. 49), então, define discurso como

a reverberação de uma verdade nascendo diante de seus próprios olhos; e, quando tudo pode, enfim, tomar a forma do discurso, quando tudo pode ser dito e o discurso pode ser dito a propósito de tudo, isso se dá porque todas as coisas, tendo manifestado e intercambiado seu sentido, podem voltar à interioridade silenciosa da consciência de si.

Os discursos são entendidos como ideológicos, isto é, sua neutralidade não é possível, pois eles estão ligados a relações de poder desiguais dentro de determinados contextos, além de reverberarem verdades construídas socialmente. É como discurso que a língua é entendida no LC. De acordo com Jordão (2013, p. 73), "a língua, que tem sua existência nas práticas sociais, é um espaço ideológico de construção e atribuição de sentidos, o que se dá num processo enunciativo sempre contingente (relativo a sujeito, tempo e espaço específicos)”. Portanto, o modo como atribuímos sentidos ao mundo são construídos socialmente nas nossas interações e 
experiências sociais. São as ideologias que permeiam a língua que permitem que o processo de construção de sentido ocorra; todas as nossas leituras são baseadas na nossa perspectiva, que não é neutra. Por isso, o LC supõe que o ensino-aprendizagem de línguas abarque o estudo do "lócus da enunciação como um todo" (JORDÃO, 2013, p. 75).

De acordo com o LC, não é possível pensar em uma única verdade, há várias delas, pois há múltiplas construções de sentido permeadas por ideologias. Podemos falar, então, de percepções da realidade. Devido a relações de poder, algumas interpretações do mundo são mais legitimadas que outras; porém, "tudo o que consideramos verdade ou mentira, acerto ou erro, são sempre leituras, interpretações localizadas e construídas cultural, social, historicamente. A possibilidade ou o desejo por discursos 'verdadeiros' é considerada ilusória" (JORDÃO, 2007, p. 26).

A pedagogia crítica (doravante PC) é, por vezes, confundida com LC. Ela concebe a língua como código ideológico, mas no sentido de que são utilizadas estratégias para distorcer a verdade. Um aprendiz crítico, nessa concepção, seria aquele capaz de perceber os sentidos reais escondidos pelas ideologias. Com base no marxismo, a PC visa a igualdade, pois o poder estaria nas mãos dos opressores, enquanto os oprimidos não teriam poder algum. Foi em consonância com esse raciocínio, embora não sejam feitas referências claras a Marx, que Freire escreveu suas obras na década de 70, influenciando também a PC. Para que o aluno se libertasse, ele deveria descobrir o que o autor quis dizer e quais estratégias foram utilizadas para persuadir o leitor. O aluno deveria perceber a verdade por trás das ideologias. Logo, havia a ideia de certo e errado, verdade e ilusão (JORDÃO, 2013; MENEZES DE SOUZA, 2011a). A partir da década de 80, Freire reconhece a importância da coletividade nas leituras, contribuindo com o LC. Freire (2005) enfatiza a importância do leitor na construção de sentidos. Não se trata de compreender o que foi lido, mas, sim de construir sentidos a partir da materialidade do texto ${ }^{3}$, por isso é necessário que haja reflexões críticas, questionamentos no que concerne essas leituras que ocorrem por causa das ideologias com as quais tivemos contato e que foram construídas e reverberadas socialmente. Menezes de Souza (2011a, p. 296) elabora um quadro comparativo, que reproduzimos abaixo, entre as teorias.

Quadro 1: quadro comparativo entre PC e LC.

${ }^{3}$ A palavra "texto" é usada para se referir a todos os tipos de textos (imagem, áudio, etc), não apenas ao escrito. 


\begin{tabular}{|c|c|}
\hline Consciência crítica tradicional: & Consciência crítica redefinida: \\
\hline Pedagogia Crítica. & Letramento Crítico \\
\hline $\begin{array}{l}\text { Enfoque na escritura do texto: } \\
\text { Como o Outro produziu a sig- } \\
\text { nificacão? }\end{array}$ & $\begin{array}{l}\text { Enfoque na leitura do texto: } \\
\text { como o Eu produz a significação. }\end{array}$ \\
\hline $\begin{array}{l}\text { Todas as leituras são homogêne- } \\
\text { as, iguais. }\end{array}$ & $\begin{array}{l}\text { As leituras/escrituras só serão } \\
\text { iguais se forem produzidas por lei- } \\
\text { tores/escritores de coletividades so- } \\
\text { ciais iguais. Senão serão desiguais. }\end{array}$ \\
\hline $\begin{array}{l}\text { Poder dividido entre dominante } \\
\text { e oprimido. }\end{array}$ & $\begin{array}{l}\text { Poder distribuído entre todos, po- } \\
\text { rém de formas desiguais (Foucault). }\end{array}$ \\
\hline Leitura como consenso. & Leitura como dissenso, conflitante. \\
\hline $\begin{array}{l}\text { Por que o outro escreveu assim? } \\
\text { Por que o outro diz } X \text { e quer } \\
\text { dizer } Y \text { ? }\end{array}$ & $\begin{array}{l}\text { Por que eu entendilele entendeu } \\
\text { assim? Por que eu acholele acha } \\
\text { isso natural/óbvio/inaceitável? }\end{array}$ \\
\hline
\end{tabular}

Fonte: Menezes de Souza (2011a, p. 296).

O autor (2011a, p. 296, ênfase do autor) afirma que é preciso que o leitor assuma responsabilidade pelas suas leituras e reflita sobre elas. Ele, então, define LC como:

não apenas ler, mas ler, se lendo, ou seja ficar consciente o tempo inteiro de como eu estou lendo, como eu estou construindo o significado... e não achar que a leitura é um processo transparente, o que eu leio é aquilo que está escrito... Pensar sempre: por que entendi assim? Por que acho isso? De onde vieram as minhas ideias, as minhas interpretações?

É justamente porque o processo de leitura ocorre pela construção de sentidos no LC, que sempre haverá conflitos, diferenças. Por isso, em vez de buscar a igualdade - que é inalcançável por pressupor homogeneização de crenças, interações e experiências sociais - é necessário mostrar aos alunos que devemos conviver com a diferença, que ela não é errada, é apenas diferente do 'eu' - base pela qual julga-se o outro como diferente. É preciso que percebamos que nossas interpretações têm consequências no mundo (MENEZES DE SOUZA, 2011a; MENEZES DE SOUZA, 2011b).

Nossas leituras têm consequências sociais porque o social nos constrói, ao mesmo tempo em que construímos o social, de acordo com Janks (2012, p. 151), que acrescenta que "essa relação dialética é fluida e dinâmica, criando possibilidades para ação e mudança social". A autora usa o termo "crítica" como sinônimo de desconstrução, no sentido de que ser crítico é estar consciente de que somos interpelados por discursos ideológicos e perceber que ideologias constituem nossas leituras e/ou produções de textos, e então, desconstruí-las para construir 
novas interpretações, igualmente ideológicas, mas sobre as quais temos consciência. Os processos de desconstrução e reconstrução são contínuos e constantes, pois as ideologias nos cercam.

Talvez o que eu sugiro ser crítica - a habilidade de reconhecer que os interesses dos textos nem sempre coincidem com os interesses de todos e que eles estão abertos à reconstrução; a habilidade de entender que discursos nos produzem, falam através de nós e podem, entretanto, ser desafiados e mudamos; a habilidade de imaginar os efeitos possíveis e reais de textos e avaliá-los em relação a uma ética de justiça social e cuidado - não é o mesmo que sugerem os que acreditam que o letramento crítico já teve seu dia. No mundo em que vivo, envolvimento crítico com as maneiras como produzimos e consumimos significado, quais significados contam e quais são dispensados, quem fala e quem é silenciado, quem se beneficia e quem é prejudicado - continuam a sugerir a importância de uma educação no letramento crítico, e, de fato, crítica. (JANKS, 2012, p. 159, nossa tradução). ${ }^{4}$

A autora reforça a importância de inserir o LC nas práticas de ensino; pois, conscientes das ideologias que nos perpassam, podemos agir sobre os significados que construímos e sobre os textos que produzimos, como consequência, também agimos na sociedade em que estamos inseridos. No tópico seguinte, discutimos um plano de aula que é baseado no LC, refletindo acerca do desafio de estimular os alunos a refletirem sobre suas próprias interpretações.

\section{Apresentação e discussão do plano de aulas}

O plano de aula em questão foi elaborado por cinco professoras em formação inicial ${ }^{5}$ como atividade avaliativa da disciplina de 'Metodologia de Ensino de Língua Inglesa I', ofertada pelo Departamento de Letras Estrangeiras da Universidade Federal de Sergipe (UFS). Nos foi proposto que incorporássemos ao plano de aulas, ao menos, três metodologias de ensino

\footnotetext{
${ }^{4}$ As traduções neste artigo são responsabilidade das autoras. Versão original da citação: Perhaps what I mean by critique - the ability to recognise that the interests of texts do not always coincide with the interests of all and that they are open to reconstruction; the ability to understand that discourses produce us, speak through us and can nevertheless be challenged and changed; the ability to imagine the possible and actual effects of texts and to evaluate these in relation to an ethics of social justice and care - is not the same as for those who believe that critical literacy has had its day. In the world in which I live, critical engagement with the ways in which we produce and consume meaning, whose meanings count and whose are dismissed, who speaks and who is silenced, who benefits and who is disadvantaged - continue to suggest the importance of an education in critical literacy, and indeed critique (JANKS, 2012, p. 159).

${ }^{5}$ Além das autoras deste artigo, participaram da elaboração do plano: Anne Carolayne Ramiro dos Santos; Giulia Pereira Santos; e Ingrid Mikaelle Nascimento Santos. Todas elas estão cientes da produção deste artigo e autorizaram o uso do plano de aulas por nós elaborado.
} 
de línguas que identificaremos e explicaremos neste tópico. No entanto, essas metodologias deveriam ser abordadas a partir do ponto de vista do LC.

O público-alvo escolhido para as aulas foi uma turma de $8^{\circ}$ ano do Ensino Fundamental de uma escola pública regular e o objetivo geral definido foi "produzir uma agenda de planos para o fim de semana utilizando o going to, partindo do pressuposto de que as classes sociais podem influenciar/limitar as possibilidades desses planos". A aula não seria desenvolvida em uma escola pública, mas deveria ser pensada para esse contexto; o $8^{\circ}$ ano foi escolhido após a definição do assunto a ser abordado, já que going to é previsto para essa série, de acordo com o que é proposto na BNCC (BRASIL, 2017). Na elaboração do objetivo geral, procuramos incluir o aspecto linguístico a ser trabalhado (o futuro com going to, assim como a prática de escrita), um gênero textual em que esse aspecto é utilizado, para que o uso da estrutura gramatical fosse contextualizado, e um tipo de diversidade (social). De acordo com a teoria do LC, a língua não deve ser trabalhada de forma dissociada da crítica, justamente por se tratar de uma construção social permeada por ideologias. Por esse motivo, na preparação da aula, houve uma preocupação em incorporar o LC em todo o plano, de modo que a teoria perpassasse todas as atividades propostas, sem que ficasse concentrada em apenas um momento isolado da aula.

É comum ver aulas em que o LC aparece em apenas um momento/atividade, geralmente esse momento é a discussão de um tema ligado a diversidade (de gênero, racial, social, de idade etc.). No plano sob análise, houve a proposta é de que a teoria fizesse parte de todas as atividades, porque o desenvolvimento do LC envolve um processo constante de reflexão, desconstrução e reconstrução de ideologias, em que é necessário manter uma "atitude de atenção" (JORDÃO, 2013, p. 82). As ideologias que perpassam os discursos são construídas e reforçadas socialmente, muitas vezes, durante muitos anos; dificilmente elas serão desconstruídas em alguns minutos em uma aula, por isso é necessário entender o desenvolvimento do LC como um processo contínuo.

No que diz respeito a promover discussões na sala de aula, é necessário pensar: elas podem colaborar no processo de fazer os alunos refletirem acerca de suas próprias leituras? Essa pergunta também pode ser feita no momento da elaboração de outras atividades. Há uma associação entre ser crítico e emitir opiniões sobre determinado assunto. Em uma discussão, os alunos defendem suas crenças com argumentos, na tentativa de convencer os outros a concordarem. Todas as opiniões emitidas são ideológicas, dessa forma, ao defendê-las, os alunos estão reforçando-as e tentando fazer com que outros passem a acreditar nelas. Isso acontece porque há diferentes maneiras de interpretar o mundo e cada um, provavelmente, 
acredita que a sua interpretação é a certa. Logo, corre-se o risco de cair na dicotomia certo e errado, o que está em dissonância com o que é defendido no LC. Não é possível pensar em uma verdade absoluta se tudo é entendido como leituras ideológicas contingentes (JORDÃO, 2013). Desse modo, retomamos a pergunta: nesse processo, os alunos estão refletindo sobre suas próprias leituras? Emitir opiniões não é sinônimo de ser letrado criticamente, todos podem fazêlo, pois socialmente construímos nossas convicções. É preciso questionar o porquê de acreditarmos no que acreditamos, o porquê de entendermos um assunto do modo como o fazemos; as atividades propostas devem ajudar o aluno nesse processo. Com isso, não queremos dizer que as discussões não devem mais acontecer na sala de aula - até porque elas são uma maneira de os alunos ouvirem outros pontos de vista acerca de um mesmo assunto. No entanto, é necessário pensar sobre como essas discussões irão acontecer e desenvolver estratégias para que elas contribuam com a desconstrução de ideias, não com o reforço de umas em detrimento de outras. No plano analisado, procuramos propor outros tipos de atividades para incentivar reflexões, entendendo o desenvolvimento do LC como um processo constante durante as aulas. Decidimos trabalhar com a diversidade social, associando-a ao assunto gramatical going to. Também pensamos o plano de modo que as aulas culminassem na produção de um gênero textual (agenda), para que o ensino fosse contextualizado e para que os alunos percebessem por que e para que eles estavam aprendendo o assunto.

O tempo estimado para a realização de todas as atividades foi cerca de 100 minutos (duas aulas de 50 minutos). A primeira atividade é de reconhecimento do gênero textual que seria trabalhado na aula, sendo dividida em três sessões em que imagens de gêneros textuais (carta, e-mail etc.) são mostradas aos alunos que, por sua vez, devem decidir a opção de gênero que difere das outras apresentadas. Primeiro, seriam mostradas duas receitas de comida e uma agenda; em seguida, duas cartas e uma agenda; e por fim, duas tirinhas e uma agenda. Após isso, os alunos seriam incentivados a refletir sobre o que os gêneros classificados como diferentes em cada sessão têm em comum.

Na segunda atividade, os alunos devem analisar a função e os aspectos do gênero agenda, seguindo perguntas do professor. A ideia é que eles consigam perceber, pensando em conjunto, a estrutura das frases (o tempo verbal e o motivo do uso do going to), as circunstâncias nas quais as agendas foram feitas e o que as difere. Abaixo, são apresentados exemplos de agendas com planos para o fim de semana que podem ser utilizadas nessa tarefa. 
FIGURAS 1, 2 e 3: exemplos de agenda para o fim de semana.

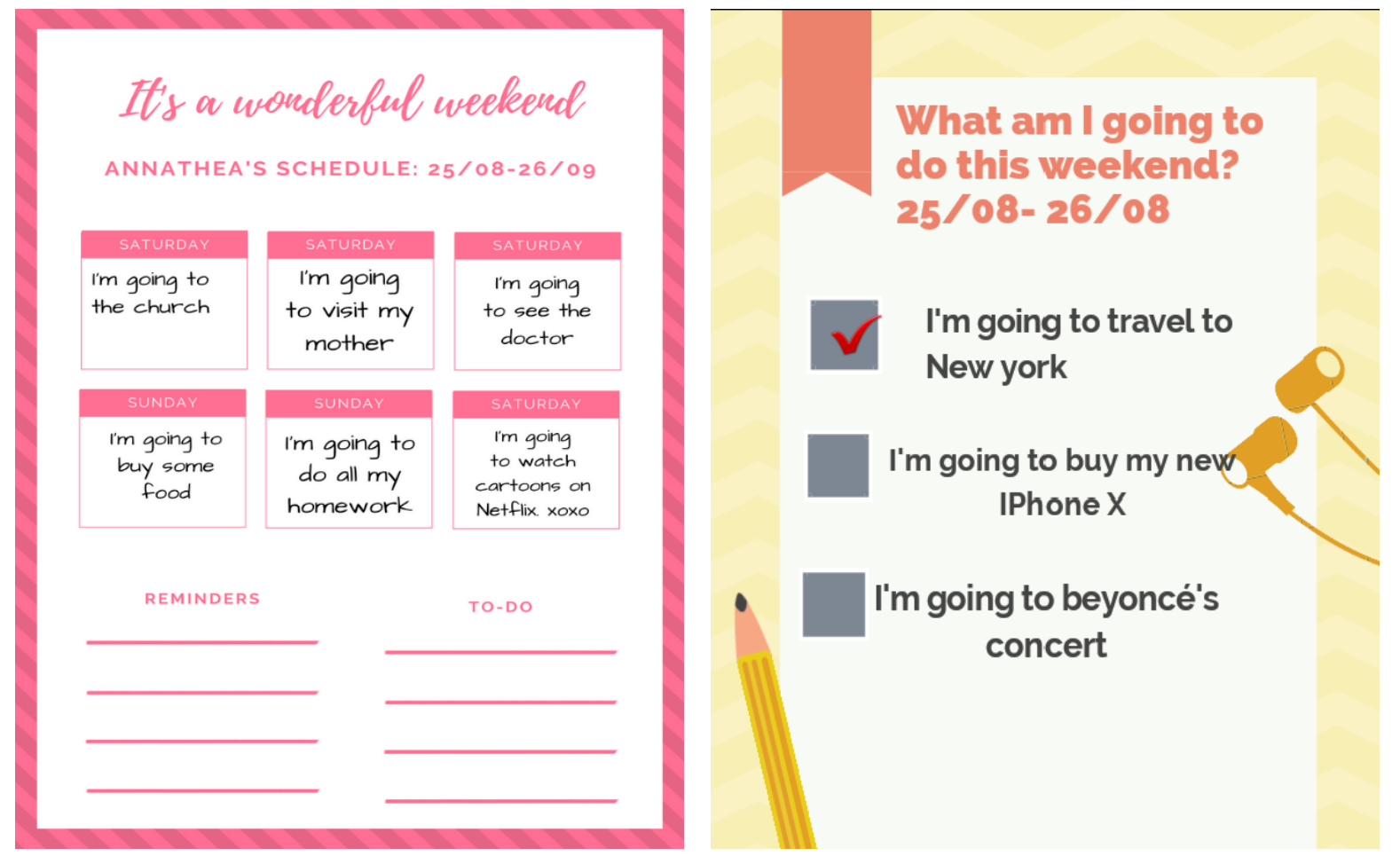

\section{WEEKEND SCHEDULE}

Amelia Jenkins • Interior Designer • ameliajenkins.com

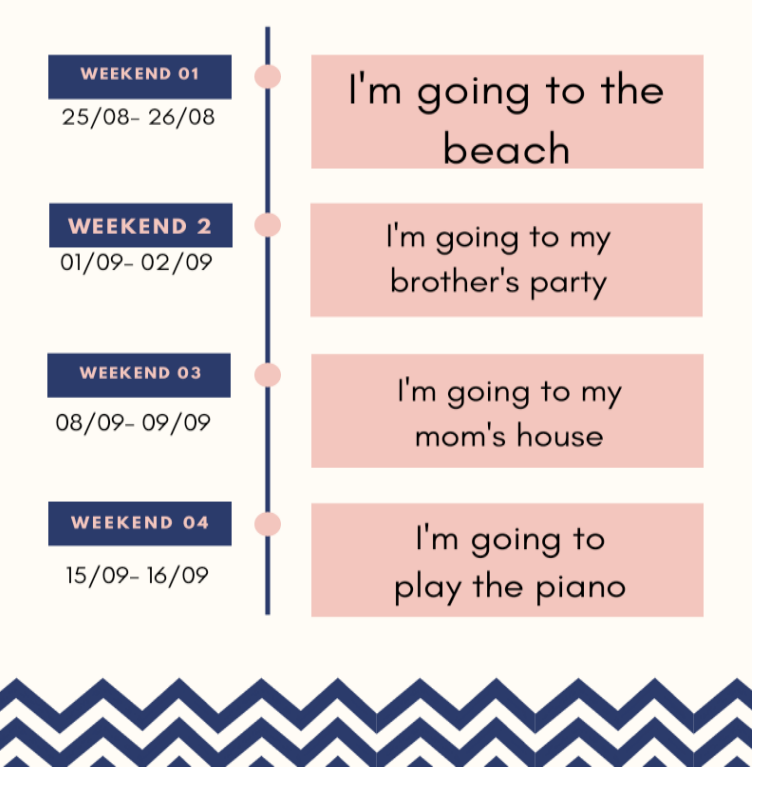


Fonte: elaboração das autoras

Nas agendas, as atividades marcadas foram pensadas de forma a fazer com que os alunos pensassem em como os planos são limitados por questões socioeconômicas. Quem pode ir à igreja? Quem pode viajar à Nova Iorque? A ideia é levar os alunos a refletirem e chegarem às suas próprias conclusões acerca do tópico da aula, trabalhando, desse modo, a gramática de forma indutiva e sem dissociá-la da crítica. Elaboramos algumas perguntas que poderiam ser utilizadas na realização dessa atividade. São elas: Qual é a função de uma agenda? Observe as sentenças nas agendas. O que elas têm em comum? Elas compartilham alguma expressão similar? Considerando a função das agendas, quando você acha que devemos usar going to? Os planos nas agendas são diferentes? Como? ${ }^{6}$

Nessa atividade, características da Abordagem Comunicativa são incorporadas. Larsen-Freeman (2003) explica que o ensino indutivo é um traço marcante dessa abordagem. Essa forma de ensinar gramática consiste numa prática em que as regras estruturais de uma língua não são explicitamente explicadas - como aconteceria com o ensino dedutivo. Os alunos devem ser guiados a concluir as regras, observando-as em usos reais da língua-alvo. Na atividade em questão, os alunos devem perceber, analisando as frases em uso em agendas gênero textual cujo objetivo é planejar ações para o futuro, a regra gramatical de um dos usos de be going to que, assim como as agendas, se refere a planos ou intenções a serem concretizados no futuro. Também procuramos despertar a atenção dos alunos para a estrutura do verbo frasal, isto é, para a flexão do verbo to be no início da expressão que é seguida por verbo no infinitivo sem o to (chamado de bare infinitive). O LC também é parte desse momento da aula, pois, como já foi mencionado, as agendas foram elaboradas de modo a demonstrar diferenças socioeconômicas em planos para o fim de semana: enquanto há o plano de ir para a praia, há outro de ir para Nova Iorque. A última pergunta proposta (se/como os planos são diferentes) visa despertar a atenção dos alunos para as relações entre planos para o fim de semana e condições socioeconômicas.

Partindo para o segundo exercício, recomenda-se que a turma seja separada em grupos cujo número de integrantes varia de acordo com a quantidade de alunos presentes na sala de

\footnotetext{
${ }^{6}$ As perguntas foram traduzidas para português, para que houvesse adequação à língua do artigo. No plano, elas estão em inglês: what is the function of a schedule? Look at the sentences in the schedules. What do they have in common? Do they share any similar expressions? Considering the function of schedules, when do you think going to is used? Are the plans in the schedules different? How?
} 
aula, que devem sortear uma das imagens de pessoas pré-selecionadas pelo professor. Nós sugerimos que as imagens representassem diferentes realidades socioeconômicas; por exemplo, podem ser escolhidas fotos de pessoas milionárias e famosas, pessoas de classe média e baixa. Depois dos grupos sortearem seu personagem e analisarem como entendem as imagens entendendo-se aqui que elas são ideológicas e que possibilitam interpretações heterogêneas, isto é, leitura como dissenso (MENEZES DE SOUZA, 2011), o professor pede para que os alunos se posicionem de pé e então diz algumas frases referentes a ações que os grupos devem gesticular, caso achem que seu personagem pode realizá-las em planos para o fim de semana, pensando na questão financeira. Novamente, a reflexão acerca de como questões socioeconômicas interferem nesses planos é proposta. Propomos frases para essa tarefa, a saber: I am going to swim in Hawaii; they are going to drink in a pub with their friends on Sunday; we are going to buy a mansion on Saturday; you are going to work next Sunday; she is going to travel in a yacht on the weekend. (Eu irei nadar no Havaí; eles irão beber em um bar com os amigos no domingo; nós iremos comprar uma mansão no sábado; você irá trabalhar próximo domingo; ela irá viajar em um iate no fim de semana.)

A metodologia incorporada nessa atividade foi a intitulada Total Physical Response, em que:

significados na língua-alvo podem ser expressos frequentemente através de ações. A memória é ativada através da resposta do aprendiz. Começar a instrução de uma língua estrangeira deve endereçar o hemisfério esquerdo do cérebro, a parte que controla comportamentos não-verbais. A língua-alvo deve ser apresentada em blocos, não apenas palavra por palavra (LARSENFREEMAN, 2003, p. 111, nossa tradução). ${ }^{7}$

Desse modo, os alunos devem praticar a estrutura gramatical através de respostas físicas. Para trabalhar o LC, no caso do plano sob análise, os alunos não deixariam de pensar na diversidade social proposta no objetivo geral da aula, pois eles só fariam os gestos se considerassem que seus personagens teriam condições socioeconômicas para tanto. Já na atividade seguinte, os alunos deveriam aproveitar o texto multimodal com o qual eles estiveram em contato anteriormente, isto é, as ações - que envolveram os modos visual (observação do professor e dos outros alunos) e o auditivo (ouvindo a fala do professor), entre outros - para

\footnotetext{
${ }^{7}$ Meaning in the target language can often be conveyed through actions. Memory is activated through learner response. Beginning foreign language instruction should address the right hemisphere of the brain, the part which controls nonverbal behavior. The target language should be presented in chunks, not just word by word. (LARSENFREEMAN, 2003, p. 111).
} 
preencher lacunas em branco das mesmas frases utilizadas na atividade prévia. Essas lacunas devem estar na flexão do verbo to be, para que os alunos percebam como ele varia de acordo com a pessoa do discurso na expressão be going to. Essa atividade foi baseada em uma técnica chamada fill-in-the-blanks, pensada a partir do Grammar-translation Method. (LARSENFREEMAN, 2003).

Em seguida, foi planejado que os alunos realizassem a leitura de um texto da área de sociologia acerca da desigualdade social, tema da aula, intitulado "The sociology of social inequality" (a sociologia da desigualdade social) de autoria de Crossman. Além do texto, a imagem que reproduzimos abaixo deveria ser mostrada.

Figura 4: imagem que ilustra a desigualdade social

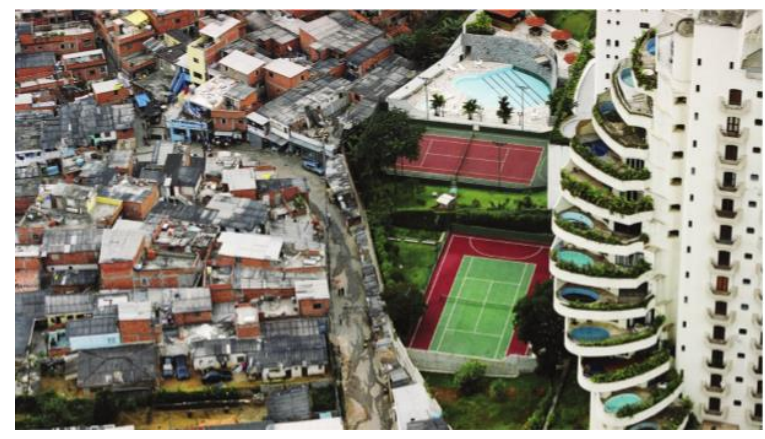

Fonte: Google ${ }^{8}$

Para ajudar os alunos no processo de compreensão e reflexão sobre o texto, foram propostas as perguntas a seguir: descreva o que você vê na imagem. Sobre o que ela é? Observe o título do texto e procure palavras que você já conhece. Qual é o provável assunto do texto? A imagem e o texto podem estar relacionados? Por quê (não)? De acordo com o texto, as pessoas têm as mesmas oportunidades? Você concorda com ele $?^{9}$ Content Based foi a metodologia utilizada nessa atividade. Como Larsen-Freeman (2003) explica, nesse caso, acredita-se que o aprendizado de uma língua se dá efetivamente quando ele é integrado ao conteúdo de uma outra disciplina, preferencialmente uma que seja de interesse dos alunos - no caso desse plano de aulas, trabalhamos a Sociologia.

Por último, planejamos a produção, em grupos, das agendas dos personagens

\footnotetext{
${ }^{8}$ Disponível em: 〈https://images.app.goo.gl/1xAUnwGdi77LPGTe8>. Acesso em 04 nov. 2018.

${ }^{9}$ Describe what you see in the image. What is it about? Observe the title of the text and look for words that you already know. What is the text probably about? Can the image and the text be related to each other? Why or why not? Do people have the same opportunities, according to the text? Do you agree with it?
} 
sorteados. Nesse momento, os alunos devem continuar refletindo sobre a desigualdade socioeconômica de forma integrada ao tópico gramatical, como foi feito durante a aula. No momento da elaboração do plano de aula, nos questionamos se seria suficiente para os alunos refletirem sobre eles mesmos, pedir para que eles fizessem agendas sobre personagens fictícios, em vez de sobre eles mesmos. Essa decisão exige que algumas questões sejam levadas em consideração. Primeiro, há o fator emocional. É possível que alguns alunos não se sintam à vontade para fazer planos para o fim de semana de acordo com suas condições socioeconômicas, pois é possível encontrar alunos que não sabem nem se terão o que comer. Logo, essa seria uma tarefa que poderia envergonhar ou excluir alunos na sala de aula. $\mathrm{O}$ segundo fator a ser considerado é a diversidade social. A atividade também tem como proposta mostrar aos alunos que há diferenças socioeconômicas: enquanto alguns são milionários, outros sobrevivem com um salário mínimo. Considerando uma sala de aula de escola pública e pensando na possibilidade de os alunos fazerem parte de uma classe socioeconômica similar, essas diferenças podem não ficar tão evidentes. Os dois fatores mencionados levam-nos a acreditar que utilizar personagens nessa atividade é a melhor opção; no entanto, há o último fator que é de extrema importância, tendo o LC em mente: a identificação. De acordo com a teoria do LC, é preciso estimular o aluno a "ler, se lendo" (2011a, p. 296). Portanto, a atividade deve levar os alunos a refletir sobre suas próprias leituras acerca da diversidade social, fazendo com que eles se percebam nesse processo - tanto como responsáveis pelas suas leituras, quanto como parte de um contexto social em que essa diversidade existe.

\section{Considerações finais}

O desenvolvimento do presente estudo possibilitou uma análise sobre o plano de aula preparado por um grupo de alunas do curso de Português e Inglês da Universidade Federal de Sergipe que tinha como princípio trabalhar a língua inglesa a partir das concepções do LC, ou seja, estimulando a prática de "ler, se lendo" (MENEZES DE SOUZA, 2011a). Discutir sobre LC na graduação do professor de letras é de suma importância; pois, essa teoria estuda e defende a relação intrínseca existente entre língua, sociedade e poder e, portanto, oferece aos graduandos uma maneira de planejar aulas para os seus futuros alunos que permitam que eles reflitam sobre a realidade que os cerca, na intenção de formar cidadãos atentos e críticos.

Dada à importância de formar alunos, não apenas visando seu desenvolvimento linguístico, mas também crítico, torna-se necessário o estímulo para o trabalho a partir da teoria 
do LC, pois o processo de reflexão começa com o professor que deve também ler suas próprias leituras e desconstruí-las. Nesse processo, o professor deve estar ainda mais atento para não impor suas crenças/verdades aos alunos, porque o objetivo é outro: encorajá-los a perceberem suas próprias leituras, para que eles construam novas, mais conscientes de suas implicações.

O plano de aula sob análise trouxe aspectos do LC em todo o seu corpo, não deixando o trabalho com a criticidade para apenas para um momento da aula, dissociando-a, desse modo da língua. Como discutimos, língua e criticidade devem ser abordados na aula de forma indissociável, pois as relações desiguais de poder estão intrínsecas nessa mesma língua. Ressaltamos a construção de sentidos foi abordada processualmente na aula, de modo a permitir que os alunos (des)construíssem as suas próprias leituras. Além disso, é importante lembrar que o aspecto linguístico da aula, uso do going to, estava totalmente conectado às questões socioeconômicas, confirmando mais uma vez que não se deve desassociar língua de práticas sociais quando se segue a filosofia do LC.

Planejar as aulas que foram analisadas envolveu processos contínuos de reflexão e questionamentos sobre o que entendemos sobre o assunto e como não impor essas leituras aos alunos, por exemplo, ao dizer a eles o que o texto lido significava, em vez de levá-los a construir sentidos e perceber o que esses sentidos implicam. É desafiador pensar em formas de fazer com que os alunos cheguem às suas próprias conclusões, sempre refletindo sobre o que elas significam e percebendo-as como construções sociais. Passar pelo processo de "ler, se lendo" (MENEZES DE SOUZA, 2011a) é difícil, de fato; guiar pessoas nesse processo é ainda mais.

\section{Referências}

BRASIL. Base Nacional Comum Curricular: Educação Infantil e Ensino Fundamental. Brasília: MEC/Secretaria de Educação Básica, 2017.

BURNS, A. Action Research. In: PALTRIDGE, B.; PHAKITI, A. Research methods in applied linguistics: a practical resource. London: Bloomsbury Academic, an imprint of Bloomsbury Publishing Plc, 2015, p. 187-204.

CROSSMAN, A. The Sociology of Social Inequality. Disponível em: <https://www.thoughtco.com/sociology-of-social-inequality-3026287>. Acesso em: 04 nov. 2018.

FREIRE, P. Pedagogia da Tolerância. São Paulo: UNESP, 2005.

FREIRE, P. Pedagogia do Oprimido. Rio de Janeiro: Paz e Terra, 1987-1994. 
FOUCAULT, M. A ordem do discurso: aula inaugural no Collège de France, pronunciada em 2 de dezembro de 1970. Tradução de Laura Fraga de Almeida Sampaio. São Paulo: Edições Loyola, 2012.

FOUCAULT, M. Arqueologia do saber. Tradução de Luiz Felipe Baeta Neves, 7 ed. Rio de Janeiro: Forense Universitária, 2008.

JANKS, H. The importance of critical literacy. English Teaching, v. 11, n. 1, p. 150-163, 2012. JORDÃO, C. M. Abordagem comunicativa, pedagogia crítica e letramento crítico - farinhas do mesmo saco? In: Rocha, C.H.; Maciel, R. F. (Org.) Língua estrangeira e formação cidadã: por entre discursos e práticas. Campinas, SP: Pontes Editores, p. 69-90, 2013.

JORDÃO, C. M. O que todos sabem.... ou não: letramento crítico e questionamento conceitual. Revista Crop, p. 21-46, 2007.

LARSEN-FREEMAN, D. Techniques and Principles in Language Teaching. 2. ed. Oxford: Oxford University Press, 2003.

LAVILLE, C.; DIONNE, J. A construção do saber: manual de metodologia da pesquisa em ciências humanas. Porto Alegre: Artmed, 1999. 344p.

MENEZES DE SOUZA, L. M. T. O Professor de Inglês e os Letramentos no século XXI: métodos ou ética? In: JORDÃO, C.M.; MARTINEZ, J.Z; HALU, R.C. (Org.). Formação (Des) formatada: práticas com professores de língua inglesa. São Paulo: Pontes, p. 279-303, 2011a. MENEZES DE SOUZA, L. M. T. Para uma redefinição de Letramento Crítico: conflito e produção de significado. In: MACIEL, R. F.; ARAÚJO, V. A. (Org.). Formação de professores de línguas: ampliando perspectivas. Jundiaí: Paco Editorial. p. 128-140, 2011 b.

RICHTER, M. G. Ensino do Português e Interatividade. Santa Maria: Ed. da UFSM, 2002. SCHULZ, L. O.; CUSTODIO, M. M. C.; VIAPIANA, S. Concepções de Língua, linguagem, ensino e aprendizagem e suas repercussões na sala de aula de língua estrangeira. PLE - Pensar Línguas $\quad$ Estrangeiras, 2012. Disponível em: <http://www.ucs.br/etc/revistas/index.php/ple/article/viewFile/1434/1088>. Acesso em: 15 mar. 2018.

VYGOTSKY, L. S. A formação social da mente. São Paulo: Martins Fontes, 1984. 